\title{
Herpes virus-like sequences are specifically found in Kaposi sarcoma lesions
}

\author{
E O’Neill, T H Henson, A J Ghorbani, M A Land, B L Webber, J V Garcia
}

Department of

Virology/Molecular

Biology, St Jude

Children's Research

Hospital, 332 North

Lauderdale, Memphis,

Tennessee, USA

E O'Neill

J V Garcia

Department of

Medicine, Division of

Dermatology,

University of

Tennessee, 956 Court

Ave E332, Memphis,

Tennessee, USA

$T$ H Henson.

A J Ghorbani

University of

Tennessee, Infectious

Disease, Baptist

Memorial Hospital,

910 Madison Suite 828,

Memphis, Tennessee,

USA

M A Land

Midsouth Pathology

Group Inc, Baptist

Memorial Hospital,

899 Madison Ave,

Memphis, Tennessee,

USA

B L Webber

Correspondence to: Dr J Victor Garcia, Department of Virology/

Molecular Biology, St Jude

Children's Research

Hospital, 332 North

Lauderdale, Memphis,

TN 38105, USA.

Accepted for publication

18 October 1995

\begin{abstract}
Aim-To detect the prevalence of herpes virus-like DNA sequences in AIDS associated Kaposi sarcoma (KSHV) lesions and normal tissue.

Methods-KSHV detection was performed by polymerase chain reaction (PCR) using four different sets of primers. PCR products were cloned, sequenced, and analysed.

Results-All of four biopsies of Kaposi sarcoma lesions and all of three paraffin embedded Kaposi sarcoma tissues were positive for KSHV, while normal tissue from the same patients was negative. Sequence analysis of amplification products revealed polymorphisms that result in amino acid changes of the predicted sequence. Conclusions-KSHV is prevalent in tissues from Kaposi sarcoma, suggesting a role in the development of the tumour. On this basis, anti-herpes virus agents should be considered to control Kaposi sarcoma. (f Clin Pathol 1996;49:306-308)
\end{abstract}

Keywords: Kaposi sarcoma, herpes virus, ORF26, BDLF-1.

Kaposi sarcoma was first recognised in middle aged European men of Mediterranean origin (classical Kaposi sarcoma), but it had also been reported in African men (African or endemic Kaposi sarcoma), in transplant associated immunosupressed individuals, and in individuals infected with HIV. ${ }^{1}$ The histology is similar in all cases, with multifocal, polyclonal tumours that show heterogeneity in cell composition but are dominated by spindle shaped endothelial cells. $^{2}$

Kaposi sarcoma is a disease of unknown aetiology and presents in an aggressive form when associated with the acquired immunodeficiency syndrome (AIDS). The fact that adoption of "safe sex" guidelines correlates with a reduction of Kaposi sarcoma in HIV infected individuals, ${ }^{1}$ and the finding of herpes viruslike sequences in Kaposi sarcoma lesions (KSHV), ${ }^{3-5}$ supports the notion that an infectious agent is responsible for Kaposi sarcoma. Furthermore, Dupin et $a l^{5}$ have amplified KSHV sequences in clinically normal skin adjacent to Kaposi sarcoma lesions, suggesting a disseminated spread of the putative virus.

To study the incidence of herpes virus-like sequences in Kaposi sarcoma lesions of AIDS patients, we performed polymerase chain reaction (PCR) on DNA obtained from biopsies and paraffin embedded blocks of tissues. We report the presence of KSHV in DNA obtained from all Kaposi sarcoma samples. However, tissue obtained from normal skin of the same patients and from an HIV seronegative control were found to be devoid of KSHV sequences. Upon sequencing of the entire open reading frame (ORF) amplification products, polymorphisms similar to those found in herpes virus saimiri and Epstein-Barr viruses ${ }^{3}$ were identified, suggesting a degree of divergence.

\section{Methods}

DNA extractions from paraffin embedded tissues and biopsies were done as described. ${ }^{67}$ The conditions for PCR amplification for biopsy samples were as follows: $25 \mu \mathrm{l}$ reactions contained $164 \mathrm{ng}$ of DNA, $100 \mu \mathrm{M}$ of each deoxynucleotide, $2 \mu \mathrm{M}$ of each primer, $2.5 \mathrm{U}$ of AmpliTaq DNA Polymerase (Perkin Elmer), and $10 \times$ PCR buffer (Perkin Elmer). The reaction consisted of an initial denaturation step at $94^{\circ} \mathrm{C}$ for 2 minutes, followed by 35 cycles of denaturation, annealing and extension, at $94^{\circ} \mathrm{C}, 61^{\circ} \mathrm{C}$, and $72^{\circ} \mathrm{C}$ respectively (1 minute each), and ended with a final extension step at $72^{\circ} \mathrm{C}$ for 5 minutes. When amplifying from paraffin embedded tissues, DNA was extracted from approximately $5 \mu \mathrm{m}$ sections, resuspended in $100 \mu$, diluted $1: 10$, and $1 \mu \mathrm{l}$ was added to the PCR mix. The PCR conditions were the same except for annealing temperature $58^{\circ} \mathrm{C}$, extension time 2 minutes, and the number of cycles 40 . The primer sequences and their relative location in the KSHV are shown in fig 1. For each DNA sample, parallel amplification of a fragment of exon 6 of the p53 gene was performed as a positive control using previously described primers. ${ }^{8}$ Separation of $8 \mu \mathrm{l}$ of the PCR amplification products was performed on $1.8 \%$ agarose gels. The gels were stained with ethidium bromide and the presence or absence of bands of expected sizes was characterised by UV visualisation. To estimate the sensitivity of this assay, $100 \mathrm{ng}$ of human genomic DNA was mixed with different amounts of a plasmid containing the KSHV sequences. Less than $0.7 \mathrm{fg}$ of plasmid was detected.

Cloning of the PCR products into the pCRII plasmid vector was done using a TA cloning kit (Invitrogen) following the manufacturer's instructions. Sequences were obtained using the chain terminator method on an ABI automatic sequencer. Sequence comparison was done using the Wisconsin GCG software package. ${ }^{9}$

\section{Results}

To determine the incidence of KSHV, genomic DNA was prepared from four individual punch biopsies obtained with informed consent from 


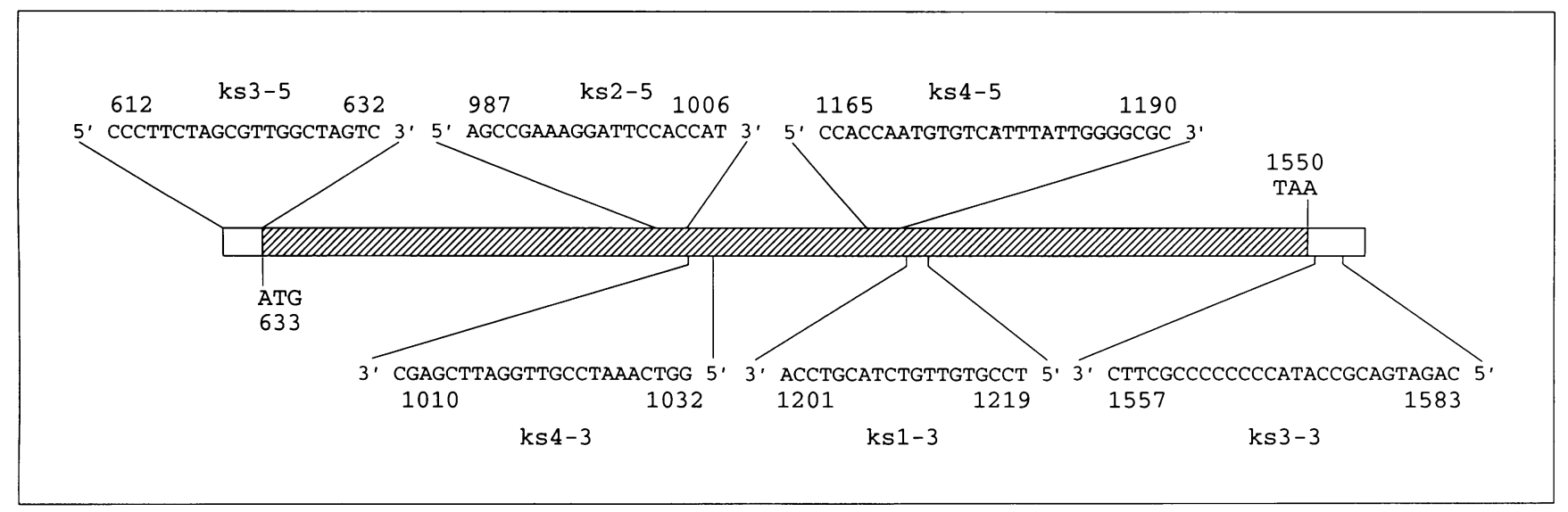

Figure 1 Primers used in this study and their relative location in the KSHV sequences homologous to BDLF1 and ORF26. The combination of primers for PCR were as follows: ks3-5/ks4-3, ks2-5/ks1-3, ks4-5/ks3-3, and ks3-5/ks3-3. The expected PCR amplification products are 421, 233, 419, and 972 bp respectively. Nucleotide sequences are numbered as in Chang et al. ${ }^{3}$

previously diagnosed Kaposi sarcoma lesions of patients with HIV infection. Genomic DNA was also prepared from sections of paraffin embedded blocks of three additional Kaposi sarcoma tissue samples from HIV infected individuals. DNA samples were amplified with primers specific for an internal fragment of KSHV previously identified by Chang et al to be homologous to the BDLF1 and ORF26 proteins of Epstein-Barr virus (EBV) and herpes virus saimiri respectively ${ }^{3}$ (fig 1 , primers $\mathrm{ks} 2-5 / \mathrm{ks} 1-3)$. As shown in fig 2 , an amplification product of $233 \mathrm{bp}$ was obtained indicating the presence of KSHV sequences homologous to BDLF1 and ORF26 in all the samples. The difference in staining intensity of some of the samples obtained from the paraffin embedded tissue blocks reflects the difficulty in quantitative recovery of DNA from such samples. To determine if KSHV sequences were present in non-KS samples from patients 1-4 and a normal HIV seronegative control, DNA samples were subjected to PCR amplification and analysis as in fig 2 . None of the control samples or the non-Kaposi-sarcoma samples from patients 1-4 showed detectable levels of the $233 \mathrm{bp}$ amplification product. However, all contained amplifiable DNA as determined by amplification of a fragment of exon 6 of the p53 gene (fig 3). These results indicate that the KSHV sequences are con-

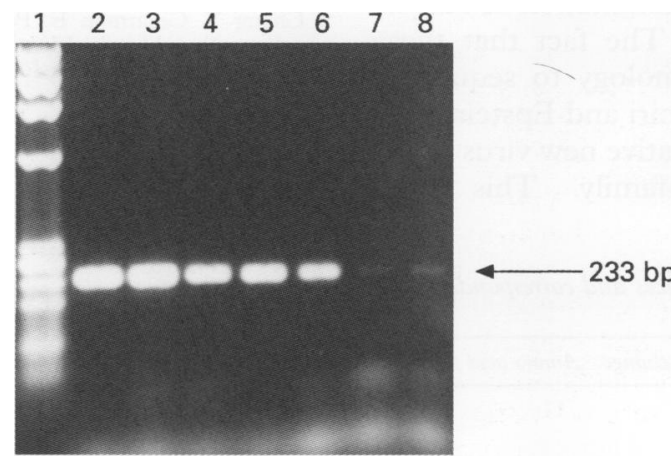

Figure 2 Amplification of a 233 bp internal fragment of the KSHV region homologous to BDLF1 and ORF26.

The lanes correspond to: (1) HaeIII digested X174 DNA markers; (2-5) DNA from Kaposi sarcoma tissue biopsies of patients 1-4; (6-8) DNA from paraffin embedded Kaposi sarcoma tissue samples from patients 5-7. centrated at the sites of the lesions and not disseminated throughout the skin.

Sequence analysis of the $233 \mathrm{bp}$ amplification product suggested the presence of sequence variations between the different samples (see below). These differences could affect the efficient amplification of KSHV sequences found in Kaposi sarcoma samples. Therefore, two different sets of primers were designed which would amplify the $5^{\prime} 421 \mathrm{bp}$ and the $3^{\prime} 419 \mathrm{bp}$ of the BDLF1/ORF26-homologous gene. Also, the outermost $5^{\prime}$ and $3^{\prime}$ primers were used to amplify the entire coding sequence. As indicated in fig 4 , these three combinations of primers efficiently amplify the KSHV sequences, resulting in amplification products with the appropriate sizes. These results confirm the presence of the entire gene in the samples and show the efficiency of each of these combinations of primers in amplifying KSHV sequences in Kaposi sarcoma samples.

As indicated above, preliminary sequencing of the $233 \mathrm{bp}$ amplification product from the BDLF1/ORF26-homologous gene suggested

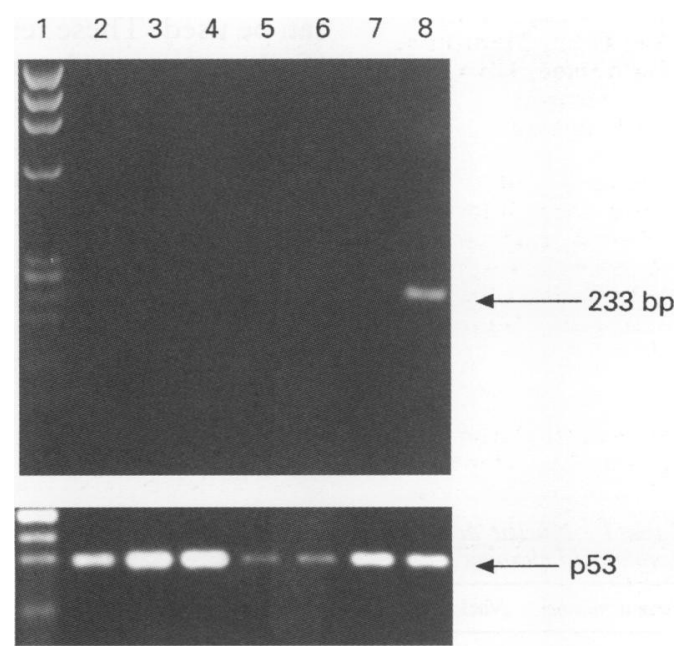

Figure $3 P C R$ amplification of control tissue samples. The lanes correspond to: (1) HaelII digested X174 DNA markers; (2) DNA from tissue of an HIV seronegative control; (3-6) DNA from normal tissue of patients 1-4; (7) $D N A$ from CEM cells; (8) DNA from Kaposi sarcoma tissue of patient 1; (bottom) amplification of a fragment of exon 6 of the p53 gene of the above sample (in the same order). 


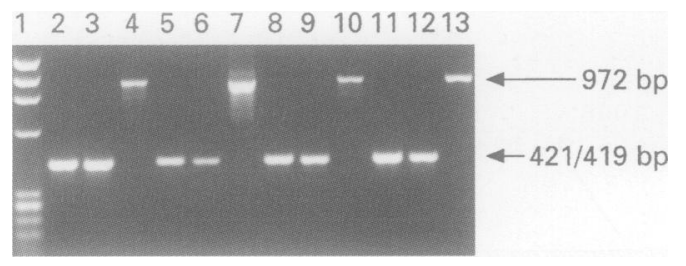

Figure 4 Amplification of the $5^{\prime}$ and $3^{\prime}$ ends and entire sequence of the KSHV homologous to BDLF1 and ORF26. The lanes correspond to: (1) HaeIII digested X174 DNA markers; (2-4) DNA from Kaposi sarcoma tissue of patient 1 ; (5-7) DNA from Kaposi sarcoma tissue of patient 2; (8-10) DNA amplification product from Kaposi sarcoma tissue of patient 3; (11-13) DNA from Kaposi sarcoma tissue of patient $4 ;(2,5,8,11)$ amplification of $5^{\prime}$ end of the KSHV ORF using ks3-5 and $k s 4-3$ primers; $(3,6,9,12)$ amplification of $3^{\prime}$ end of HVLS using ks4-5 and ks3-3 primers; $(4,7,10,13)$ amplification of entire ORF sequence using ks3-5 and ks3-3 primers.

the presence of sequences different from those originally reported by Chang et al. ${ }^{3}$ Therefore, the entire ORF product obtained from three of the biopsies was sequenced and analysed. As shown in table 1, eight nucleotide changes were identified, four of which resulted in amino acid substitutions at amino acids $11(\mathrm{~F} \rightarrow \mathrm{L})$, $113(\mathrm{~V} \rightarrow \mathrm{G}), 134(\mathrm{P} \rightarrow \mathrm{I})$, and $167(\mathrm{D} \rightarrow \mathrm{G})$. These results suggest the possibility of herpes virus strain differences that might be present in different groups of Kaposi sarcoma patients.

\section{Discussion}

In this study, KSHV sequences were found in all the Kaposi sarcoma lesions examined. The presence of KSHV was not observed in nonKaposi sarcoma or control tissues. Under the experimental conditions used, less than $0.7 \mathrm{fg}$ of plasmid DNA containing the entire ORF mixed with $100 \mathrm{ng}$ of genomic DNA could be detected. In specific situations were sensitivity might need to be increased, a nested PCR procedure using the external set of primers described here in combination with the original set of primers described by Chang et al ${ }^{\beta}$ (fig 1) can be used. These results, together with those of others, ${ }^{35}$ strongly suggest that the prevalence of a putative new herpes virus in Kaposi sarcoma lesions is linked to the pathogenesis of the disease. To date, no group (including ours) has reported the identification of viral particles by electron microscopy examination of Kaposi sarcoma tissue samples. The fact that these viral sequences have homology to sequences found in herpes virus saimiri and Epstein-Barr virus would place this putative new virus in the Gammaherpesvirinae subfamily. This clas-

Table 1 Nucleic acid changes in herpes virus-like DNA sequences and corresponding amino acid changes ${ }^{1}$

\begin{tabular}{llclc}
\hline Patient number & Nucleotide change & Nucleotide position & Amino acid change & Amino acid position \\
\hline 3,4 & $\mathrm{~T} \rightarrow \mathrm{C}$ & 663 & $\mathrm{~F} \rightarrow \mathrm{L}$ & 11 \\
3,4 & $\mathrm{~T} \rightarrow \mathrm{C}$ & 683 & & \\
3,4 & $\mathrm{~T} \rightarrow \mathrm{C}$ & 686 & $\mathrm{~V} \rightarrow \mathrm{G}$ & 113 \\
1,3 & $\mathrm{~T} \rightarrow \mathrm{G}$ & 970 & $\mathrm{P} \rightarrow \mathrm{I}$ & 134 \\
3 & $\mathrm{C} \rightarrow \mathrm{A}$ & 1032 & & 167 \\
3 & $\mathrm{G} \rightarrow \mathrm{T}$ & 1055 & $\mathrm{D} \rightarrow \mathrm{G}$ & \\
3 & $\mathrm{~A} \rightarrow \mathrm{G}$ & 1132 & & \\
3 & $\mathrm{~A} \rightarrow \mathrm{C}$ & 1139 & & \\
\hline
\end{tabular}

${ }^{1}$ Open reading frame and amino acid sequences are numbered according to Chang et al. ${ }^{3}$ sification includes viruses capable of establishing latent infections and also capable of inducing cell transformation, two properties that describe the putative new virus. Viruses in the Gammaherpesvirinae subfamily are typically 150 kilobases of size. The KSHV sequences published to date comprise only a small portion of this novel herpes virus. Because PCR has been employed to generate all the available fragments of $\mathrm{KSHV}$, the apparent polymorphisms described should be confirmed by direct sequencing of viral DNA fragments. However, if confirmed, the sequence differences found might help in the classification of this virus and help identify individual strains of KSHV. Future efforts to clone more viral sequences should also assist in the proper classification of this virus. The presence of putative polymorphism in KSHV raises the possibility of strain differences which might have different properties. Because different types of neoplasm have been associated with KSHV it will be important to determine any possible correlation between the different sequences and disease.

It has been suggested that transcripts corresponding to the putative new virus are found in Kaposi sarcoma samples. ${ }^{4}$ However, no data were presented by the authors and no information was provided about which genes are expressed. Although some viral gene expression would be expected, with the limited sequence information available it might be difficult to identify viral transcripts. The lack of observable virus particles in Kaposi sarcoma samples suggest that the virus is present in a latent state. Therefore, efforts towards inducing virus expression might prove helpful in its isolation. Based on the accumulating evidence suggesting the role of a herpes virus in the development of Kaposi sarcoma, anti-herpes virus agents should be considered to control the tumour.

We thank Dr Y Chang for providing us with a PCR amplification product that was used as a positive control. Drs J Sample, A d'Azzo,and J Foster are thanked for their comments on this manuscript. This work was funded by grants CA-59175 (JVG) Cancer Center Support (CORE) grant CA-21765 from the National Cancer Institute, and by the American Lebanese Syrian Associated Charities (ALSAC) of St Jude Children's Research Hospital.

1 Levy JA. HIV infection and the development of cancer. In Levy JA, ed. HIV and the pathogenesis of AIDS. Washington, DC: ASM Press, 1994:181-98.

2 Regezi JA, Macphail LA, Daniels TE, DeSouza YG, Greenspan JS, Greenspan D. Human immunodeficiency virusassociated oral Kaposi's sarcoma. Am f Pathol 1993;143. 240-9.

3 Chang Y, Cesarman E, Pessin MS, Lee F, Culpepper J Knowles DM, et al. Identification of herpes virus-like DNA sequences in AIDS-associated Kaposi's sarcoma. Science sequences in AID

4 Huang YQ, Li JJ, Kaplan MH, Poiesz B, Katabira E, Zhang WC, et al. Human herpes virus-like nucleic acid in various forms of Kaposi's sarcoma. Lancet 1995;345:759-61.

5 Dupin N, Grandadam M, Calvez V, Gorin I, Aubin JT, Havard $S$, et al. Herpes virus-like DNA sequences in patients with Mediterranean Kaposi's sarcoma. Lancet 1995;345:761-2.

6 Kawasaki ES. Sample preparation from blood, cells, and other fluids. In: Innis MA, Gelfand DH, Sninsky JJ, White TJ, eds. PCR protocols - a guide to methods and applications. San Diego: Academic Press, 1990:146-52.

7 Wright DK, Manos MM. Sample preparation from paraffinembedded tissues. In: Innis MA, Gelfand DH, Sninsky J White TJ, eds PCR protocols - a guide to methods and applications. San Diego: Academic Press, 1990:153-8.

8 Gaidano G, Ballerini P, Gong JZ, Inghirami G, Neri A, Newo G, Ballerini $P$, Gong JZ, Inghrami $G$, Neri A, Newcomb EW, et al. p53 mutations in human lymphoid malignancies: association with Burkitt lymphoma and 1991;88:5413-17.

9 Program manual for the Wisconsin package, Version 8. Genetics Computer Group, 1994. 